\title{
A ÁREA DE EDUCAÇÃO NO CURSO DE LICENCIATURA DE CIÊNCIAS SOCIAIS
}

\author{
Ricardo CUSINATO ${ }^{1}$
}

RESUMO: O trabalho tem por objetivo analisar o currículo da área de educação curso de licenciatura em Ciências Sociais. Inicialmente, é feito um breve histórico do ensino superior no Brasil nas últimas décadas. Em seguida é apresentada e discutida a evolução da estrutura curricular da área de educação das licenciaturas. Finalmente, são feitas críticas e sugestões para uma redefinição do currículo das licenciaturas, considerando uma contribuição para os cursos de formação de professores.

PALAVRAS-CHAVE: Licenciatura. Formação de professores. Currículo.

\section{Introdução}

O objetivo deste trabalho é analisar a evolução do currículo do curso de Licenciatura de Ciências Sociais na UNESP de Araraquara. Este curso existe em Araraquara, desde o ano de 1950, com na Faculdade de Filosofia, Ciências e Letras de Araraquara, que, na época era um Instituto isolado. Na década de 70, a Faculdade de Filosofia Ciências e Letras de Araraquara foi incorporada à Universidade Estadual Julio de Mesquita Filho - UNESP.

É importante fazer referência à história da educação superior no Brasil, mesmo que de forma breve, para que se entenda o ensino superior dos dias atuais.

\section{A Universidade e o contexto histórico}

No Brasil, o ensino superior foi instituído com ma vinda da família real portuguesa, em 1808, com a criação dos primeiros cursos superiores de Medicina, Direito e Engenharia.

\footnotetext{
${ }^{1}$ UNESP - Universidade Estadual Paulista. Faculdade de Ciências e Letras - Departamento de Didática. Araraquara - SP - Brasil. 14800-901 - cusinato@fclar.unesp.br
} 
As instituições superiores eram isoladas e mantidas pelo Estado, com o objetivo de formar profissionais que atenderiam às necessidades da sociedade e do próprio Estado.

Por determinação legal, em 1920, é instituída a Universidade, equivalendo ao agrupamento de quatro faculdades isoladas. No entanto, somente iniciando o seu funcionamento em 1937.

O Brasil viveu a ditadura militar instaurada em 1964, com suas características sórdidas de autoritarismo, do terror e das reformas institucionais. De acordo com Hilsdorf (2003, p.122):

[...] começava o período do governo militar, com seu regime centralizado e coercitivo e no campo da educação, as políticas implementadas no período, segundo o enquadramento do desenvolvimentismo e da segurança nacional, vão sendo realizadas sob a justificativa ideológica liberal de que se investia na melhoria do "capital humano", para adequar a sociedade brasileira aos patamares das exigências modernas da produção internacional. O processo educacional deve estar ligado ao desenvolvimento e é considerado como um investimento que redunda em maior produtividade".

Entre 1964 e 1968, ouvia-se falar dos acordos MEC-USAID e, depois soube-se que os americanos ofereciam ajuda para financiar programas para garantir a conquista de graus escolares mais elevados, o que proporcionaria a ascensão social: “[...] foram assinados 12 acordos MECUSAID, com a finalidade de diagnosticar e solucionar problemas da educação brasileira na linha do desenvolvimento internacional baseado no capital humano.” (HILSDORF, 2003, p.124).

A mentalidade dos assessores dos acordos e mais as mentalidades dos militares, definiram os aspectos da política educacional desse período, que são: o desenvolvimentismo, a produtividade, a eficiência, o controle e a repressão.

No entanto, havia uma contradição entre a ideologia política do nacionalismo desenvolvimentista e o modelo de regime vigente, político e econômico. Essa contradição se reflete na educação. Como diz Saviani (1987, p.83):

Em termos educacionais, foi exatamente no período em que aflora a contradição antes referida que se ensaiou uma abertura maior na direção das aspirações populares, surgindo iniciativas como o Movimento de Educação de Base (MEB), as campanhas de alfabetização de adultos, os Centros de Cultura popular etc. Isso porém, ocorreu à margem da organização escolar regular, construindo uma espécie de "sistema paralelo" para onde os estudantes universitários canalizavam seus anseios de reforma compensando, assim, o não-atendimento de suas reivindicações pela reforma da própria universidade”. 
Agravados os problemas, a universidade se torna palco e alvo das reivindicações reformistas. Por outro lado, o governo tomava algumas medidas visando enquadrar o movimento estudantil e a universidade nas diretrizes do novo regime.

Os estudantes decidiram fazer a reforma pelas próprias mãos: em julho de 1968, ocuparam as universidades, instalaram cursos-piloto. Desse modo, algumas escolas ficaram sob o controle dos alunos durante praticamente todo o segundo semestre (SAVIANI, 1987). Em outubro de 1968, entrava na ordem do dia do Congresso Nacional o projeto de lei $n^{\circ} 32$, destinado a fixar "[...] as normas de organização e funcionalidade do ensino superior e sua articulação com a escola média e dar outras providências.” (SAVIANI, 1987, p.85).

A discussão em torno do projeto tinha que ser rápido, pois era preciso desalojar os alunos do controle das escolas e estabelecer a ordem; a minoria aprovou pacificamente o projeto e "[...] dir-se-ia que a oposição consentida consentiu na aprovação do projeto do governo” (SAVIANI, 1987, p.91).

É importante destacar o significado político do texto aprovado, a Lei $n^{\circ} 5540 / 68$, que é um produto típico do regime político instaurado com o golpe militar de 1964. De acordo com Saviani (1987, p.92), ao explicitarmos o sentido do referido golpe, podemos dizer que o movimento militar de 1964 traduziu a opção pelo ajustamento da ideologia política ao modelo econômico. Para isso era preciso operar uma ruptura política: “[...] as Forças Armadas se levantaram para salvaguardar as tradições, restaurar a autoridade, manter a ordem, preservar as instituições e defender a democracia contra as ameaças da desordem, da subversão e do totalitarismo.”

Essa mudança política se caracterizou por uma crescente centralização e, de forma desproporcional, fortaleceu a sociedade política e enfraqueceu a sociedade civil.

Em conseqüência disso, a sociedade política, que para se manter usa a força, perdeu o apoio da sociedade civil.

Como afirma Saviani (1987, p.93): “[...] Eis por que, nos últimos anos, se difundiu a distinção entre legalidade e legitimidade. Quer dizer, o governo é legal porque estribado nas leis que ele próprio patrocinou; não é, porém, legítimo, já que não conta com o consentimento ativo dos governados.”

A recordação que se tem dessa época é que, em quase todas as classes dos cursos da Faculdade de Filosofia, Ciências e Letras de Araraquara, principalmente no curso de Ciências 
Sociais, tinha um aluno-espião, talvez quem sabe um membro da ADESG (Associação dos Estagiários da Escola Superior de Guerra).

Este fato demonstra que o poder militar acionou mecanismos preventivos, repressivos e operativos, ou seja, montavam verdadeiras operações militares com a finalidade de eliminar, psicológica e fisicamente, seus adversários.

Instalou-se como diz Saviani (1987,p.94) “uma democracia excludente”, pois o regime militar que proclamava pretensões democráticas operava a exclusão sistemática de vários setores da sociedade civil do processo político.

Pode-se dizer que foi desencadeado, em todo o território nacional, um processo de desmobilização social por meio do autoritarismo e pelo uso de uma violência institucionalizada.

Voltando à reforma universitária, pode-se dizer, agora, que a modernização da economia, o desenvolvimento centrado na ação das empresas multinacionais, fazia da escolarização a principal via de ascensão social. As camadas médias da sociedade faziam pressão para que houvesse a "democratização da universidade". Mas, no plano educacional também se fez necessária uma ruptura política para manter a continuidade social, ou seja, era preciso um ajustamento da política educacional à nova ideologia política.

A Lei $n^{0}$ 5540, de 28/11/1968, foi seguida do Ato Institucional $n^{0}$ 5, de 13/12/68 (AI 5) e pelos Decretos-leis $n^{\circ} 464$ e $n^{\circ} 477$, de fevereiro de 1969. Todos consumaram esta ruptura política e os estudantes universitários foram excluídos, deliberadamente, do regime que se dizia democrático. As suas falas foram silenciadas.

Desse modo, a partir de 1969, ocorreram as seguintes alterações:

a) um modelo único de instituição de ensino superior em que o ensino está indissociável da pesquisa, ou seja, a pesquisa está inserida no cotidiano acadêmico;

b) a instituição dos Departamentos, como “[...] a menor fração da estrutura universitária para todos os efeitos de organização administrativa, didático-científica e de distribuição de pessoal [...]”, compreendendo disciplinas afins;

c) regime de matrícula semestral e por disciplina;

d) o regime de créditos, como unidade de medida, parcelando os cursos;

e) vestibular unificado para todos os cursos da mesma instituição;

f) a universidade como ambiente prioritário para o desenvolvimento do ensino superior, embora permita a existência dos estabelecimentos isolados; 
g) renovação periódica do reconhecimento de universidades e estabelecimentos isolados de ensino superior.

Esses dispositivos tiveram um significado político importante: a desmobilização dos alunos que não mais formariam turmas e grupos e a transmissão dos conteúdos de forma estanque.

A reforma universitária aconteceu e de forma “[...] extensa e profunda. De alto impacto,dada a forte repressão política a que foi submetida a instituição universitária no período de sua implantação e a natureza transformadora das medidas por ela introduzidas.” (MACEDO, 2005, p.129)

O modelo de ensino superior da reforma de 1968 teve um grande crescimento na década de 1970, mas como diz Macedo (2005, p.129):

Sem instrumentos próprios e, sobretudo, sem uma clara concepção a respeito da natureza e modalidade de articulação com a sociedade da qual faz parte, nesse primeiro período a universidade brasileira limitou sua atividade nessa área ou a responder a demandas pontuais do setor produtivo ou a implementar projetos de prestação de serviços no setor da saúde ou na formação e aperfeiçoamento de professores, aproveitando o estoque de recursos e de competências de que já dispunha nessas áreas.

No entanto, ao longo dos anos 70, devido às diversas normas e regulamentos, houve “[...] a expansão do sistema nacional de educação superior pela criação de faculdades isoladas, evidência forte do fracasso do projeto de modelo único de organização.” (MACEDO, 2005, 129).

\section{O curso de ciências sociais}

Uma das importantes tarefas a ser cumprida pelas instituições de ensino superior é a formação de professores, por meio dos cursos de licenciatura.

O curso de Licenciatura é uma modalidade de curso universitário profissionalizante, que tem como objetivo formar o professor para o magistério na educação básica (ensino fundamental e médio).

Os cursos de licenciatura são compostos de, aproximadamente, 2.500 (duas mil e quinhentas) horas, sendo uma grande maioria destas horas, aproximadamente $80 \%$, destinadas a formação de conteúdos específicos de cada área do conhecimentos, como matemática, letras, 
história, por exemplo. Conteúdos estes que são desenvolvidos sob a forma de temas, conceitos e metodologia de conteúdos das disciplinas específicas e aproximadamente $20 \%$ (vinte) por cento de formação educacional.

Em linhas gerais, nos últimos cinqüenta anos, são as exigências de carga horária do MEC para a formação e autorização profissional de formação de professores.

Dentro da universidade a distinção entre as duas modalidades do ensino superior licenciatura e bacharelado- separando pesquisa de ensino, criou em alguns cursos, como é o caso do curso de Ciências Sociais, um certo constrangimento para os licenciados, quando somente é valorizado o bacharel.

Desse modo, para se ter uma idéia da posição do curso de licenciatura de Ciências Sociais, é necessária a análise do currículo do curso de Ciências Sociais. Os quadros abaixo apresentam as disciplinas oferecidas e a respectiva carga horária por ano considerado:

\begin{tabular}{|c|c|c|}
\hline ANO & DISCIPLINA & $\mathrm{CH}$ \\
\hline \multirow{4}{*}{1972} & Antropologia Física (anual) & 128 \\
\hline & Inglês (optativo)idem & 64 \\
\hline & História da Cultura Brasileira & 124 \\
\hline & Educação Física & 08 \\
\hline \multirow{6}{*}{1973} & Epistemologia I & 124 \\
\hline & História Econômica, Política e Social (geral) & 128 \\
\hline & Educação Física (anual) & 56 \\
\hline & Política I & 128 \\
\hline & Geografia Humana e Econômica & 116 \\
\hline & Sociologia Geral & 128 \\
\hline \multirow{6}{*}{1974} & Análise Econômica & 132 \\
\hline & Política II & 68 \\
\hline & Geografia do Brasil & 68 \\
\hline & Ética & 60 \\
\hline & Estrutura e Funcionamento do Ensino de $1^{\circ}$ e $2^{\circ}$ grau & 64 \\
\hline & Educação Física & 26 \\
\hline \multirow[t]{7}{*}{1975} & Antropologia II (Antropologia Cultural) & 64 \\
\hline & Filosofia VII (Epistemologia das Ciências Sociais) & 64 \\
\hline & História II (História do Brasil) & 64 \\
\hline & Sociologia VIII (sociologia do Conhecimento) & 56 \\
\hline & Sociologia VI (Teorias Sociológicas) & 64 \\
\hline & Estudos de Problemas Brasileiros & 32 \\
\hline & Psicologia da Educação & 64 \\
\hline
\end{tabular}




\begin{tabular}{|l|l|c|}
\hline & Educação Física & 28 \\
\cline { 2 - 3 } & Organização Social do Brasil & 60 \\
\cline { 2 - 3 } & Etnografia Brasileira & 60 \\
\cline { 2 - 3 } & Filosofia IX (O conceito de alienação) & 60 \\
\cline { 2 - 3 } & Didática Especial & 160 \\
\cline { 2 - 3 } & Didática Especial (estágio) & 60 \\
\cline { 2 - 3 } & Didática Geral & 60 \\
\cline { 2 - 3 } & Educação Física & 30 \\
\hline
\end{tabular}

Este demonstrativo, fornecido pela UNESP e referente à década de 70, demonstra que o currículo da área de educação na Licenciatura de Ciências Sociais era composto das seguintes disciplinas:

1. Estrutura e Funcionamento do Ensino de $1^{\circ}$ e $2 \bullet$ grau

2. Psicologia da Educação

3. Didática Especial ( mais os estágios)

4. Didática Geral (mais os estágios).

São quatro as disciplinas da área de Educação no currículo do curso de Licenciatura em Ciências Sociais, até a década de 1970. Estas quatro disciplinas são exigidas pelo MEC como necessárias, ou seja, como o mínimo necessário para a formação profissional do professor.

Pressupõe-se que com estas quatro disciplinas o profissional está preparado para entrar em sala de aula e desempenhar seu trabalho de professor. O MEC, no entanto, reconhece sua formação e o habilita a exercer seu trabalho acadêmico no que hoje é denominado educação básica.

As instituições credenciadas para ministrarem os cursos de Licenciatura, sejam as Faculdades ou Universidades, públicas ou particulares, oferecem apenas estas quatro disciplinas da área de educação no currículo de formação de professores. Todo o espaço restante existente dentro da carga horária é preenchido pelas disciplinas de conteúdos específicos. Elas se movimentam, alteram currículo, criam disciplinas, acrescentam temas e conceitos e, até mesmo, alteram cargas horárias. A área educacional fica estática, engessada pelas condições estruturais da própria universidade.

Na década de 90, ocorre uma mudança no currículo das licenciaturas da UNESP. As disciplinas da área da Educação, denominadas de "Pedagógicas” em alusão ao curso de Pedagogia, se mantêm. As quatro disciplinas tradicionais, porém agora chamadas de:

1.Estrutura e Funcionamento do Ensino de $1^{\circ}$ e $2^{\circ}$ grau. 
2. Psicologia da Educação.

3.Didática.

4. Prática de Ensino.

Houve uma mudança de nomenclatura nas Didáticas: de Didática Especial e Didática Geral para Didática e Prática de Ensino. Também ocorreu um acréscimo de horas de estágios: de 90 (noventa) horas para 120 (cento e vinte) horas. Mudanças insignificantes, mudanças inexpressivas, não compatíveis com as necessidades de um currículo de formação de professores para um país com a realidade social de um país em desenvolvimento como o Brasil.

Na década de 90, novamente os cursos de licenciatura passam por uma reforma curricular. Agora as disciplinas Pedagógicas dos cursos de Licenciatura, em particular o curso de Licenciatura em Ciências Sociais da UNESP de Araraquara, recebem um aumento considerável de carga horária de estágio: de 120 (cento e vinte) para 300 (trezentas) horas. São mantidas as seguintes disciplinas:

1.Estrutura e Funcionamento do Ensino.

2.Psicologia da Educação.

3.Didática.

4.Prática de Ensino.

A alteração no currículo da área educacional das disciplinas que compõem o currículo das licenciaturas nas disciplinas resume-se na nomenclatura e no aumento da carga horária dos estágios: de Estrutura e Funcionamento do Ensino de $1^{\circ}$ e $2^{\circ}$ grau para Estrutura e Funcionamento do Ensino; de 120 para 300 horas de estágios.

O currículo do curso de Licenciatura em Ciências Sociais, historicamente, se mantém inalterado numa realidade em mudança. Parece ignorar o mundo que o cerca e permanece fechado em si mesmo. A Universidade cria novos cursos - Economia, Administração Pública, expande as áreas de Letras; criam-se cursos de pós- graduação em diversas áreas na UNESP de Araraquara: Educação Escolar, Letras e diversos cursos de especialização são oferecidos com freqüência. No entanto, a graduação, com seus cursos de licenciaturas, permanece estática, a despeito de forças contrárias. A UNESP faz os Congressos de Formação de Educadores, anualmente, desde os anos 80, mas qual a contribuição que trazem às Licenciaturas? Por que as mudanças não ocorrem? 
Finalmente, durante os anos de 2005, 2006 e 2007, a UNESP desencadeou um processo de análise dos cursos de licenciatura, motivada pelas novas normas do Conselho Nacional de Educação. Foi um processo longo e árduo de debates em torno do projeto de Alteração Curricular dos Cursos de Licenciatura no Campus da UNESP de Araraquara, que envolveu todas as áreas do conhecimento que atuam nos cursos de licenciatura - Ciências Sociais, Letras e Química. Durante o processo, todas as disciplinas puderam se manifestar e puderam ser ouvidas. Foram realizadas, aproximadamente, oitenta e quatro reuniões de três a quatro horas cada uma. Foi uma verdadeira maratona, nem sempre cordial. Houve momentos, quase todos, de jogo corporativista em detrimento da formação de um profissional para atuar na realidade educacional brasileira.

O resultado do processo foi a elaboração de um novo currículo da licenciatura, aprovado em 2008 e implantado a partir de 2009 no Campus de Araraquara e na UNESP. Os projetos dos cursos de Licenciatura dentro da UNESP rejeitaram o consenso e partiram para a individualidade; não houve consenso nem mesmo entre as Licenciaturas de um mesmo Curso, de modo que cada Campus elaborou, aprovou e implantou um projeto próprio, diferenciado, como, por exemplo, a Licenciatura em Ciências Sociais do Campus de Araraquara e a de Marília, ambos da UNESP.

Novamente as alterações curriculares foram praticamente inexistentes, resultando no seguinte bloco de disciplinas:

1.Organização e Desenvolvimento do Ensino.

2.Psicologia da Educação.

3. Didática

4. Metodologia de Ensino ( $1^{\circ}$ semestre)

5. Estágios de Prática de Ensino ( $2^{\circ}$ semestre).

As alterações se limitaram à nomenclatura. A Estrutura e Funcionamento do Ensino foi alterada para Organização e Desenvolvimento do Ensino. A disciplina Prática de Ensino de Ciências Sociais, que era uma disciplina anual, foi desmembrada em duas semestrais: a Metodologia de Ensino e os Estágios de Prática de Ensino

Este processo foi impulsionado pela pressão do aumento de jornada da carga horária dos estágios: de 300 (trezentas) para 400 (quatrocentas) horas. O aumento para quatrocentas horas de estágios foi imposto pela legislação e pela Pró-Reitoria da UNESP e não contou com a aprovação de nenhum docente, em particular. É uma carga horária abusiva imposta aos cursos de Licenciatura como um todo. 
Importantes sugestões e contribuições para se pensar um curso de Licenciatura para a UNESP e para o Brasil como um todo, nem sequer foram discutidas. De início já foram descartadas, sem as devidas análises acadêmicas. De modo que o processo como um todo passou mais por questões de ordem corporativista do que por análises acadêmicas. Também esteve mais voltado para a universidade em si mesmo, com a preocupação de definição de departamentos, áreas de conhecimento, novas contratações do que por uma análise da sua contribuição para a realidade brasileira.

Estas questões acabam por transformar questões de ordem acadêmica e questões da realidade social em questões de ordem corporativista e aguçam a rivalidade e os problemas entre as áreas de conhecimento internas da universidade.

Foi ainda aprovado, por imposição, um bloco de 400 horas aulas de uma modalidade de Prática como Componente Curricular e mais 200 horas de Atividades Acadêmicas. São seiscentas horas de curso, impostas aos docentes dos cursos de licenciatura e que ninguém conseguia entender o que esta carga horária significava e como deveria ser desenvolvida, e, na verdade, para o que servia. De qualquer forma foram seiscentas horas do curso de Licenciatura que foram retiradas da sala de aula e convertidas em outras atividades, contra a vontade de todos e que representam uma grande perda para o currículo dos cursos de licenciatura, são seiscentas horas de esvaziamento de um currículo de formação de professores.

\section{Considerações finais}

Para se formar um profissional para atuar como professor na realidade e na diversidade das escolas brasileiras o mínimo que se pode oferecer enquanto um curso de licenciatura, é um conjunto de disciplinas que dêem conta da análise desta realidade. O currículo do curso de licenciatura deve oferecer como disciplinas obrigatórias aquelas que sejam capazes de dar conta desta realidade, como por exemplo, História da Educação Brasileira. Esta é uma disciplina importante, pois apresenta os conceitos da ciência e da história sociais e da economia e que leva ao trabalho destes conceitos dentro do contexto da implantação das políticas públicas e do desenvolvimento da escola brasileira nas suas múltiplas dimensões. Para isso é necessária a 
contribuição da Sociologia da Educação, da Filosofia da Educação, da Política Educacional e da Metodologia de Ensino.

Formar um professor exige que se lhe ofereça um curso de licenciatura que o capacite a fazer a análise da realidade social e que lhe dê as condições necessárias para que ele aplique seus conhecimentos, para que ele desenvolva o seu trabalho acadêmico dentro de um planejamento educacional. Existe toda uma Política Educacional, de desenvolvimento de projetos na realidade brasileira. É preciso que ele tenha conhecimento desta mesma realidade, desta diversidade, e dos projetos sociais deste país. É extremamente necessário que o currículo da formação do professor tenha como obrigatórias, no mínimo, as seguintes disciplinas:

1.História da Educação Geral.

2.História da Educação no Brasil.

3.Filosofia da Educação.

4.Sociologia da Educação

5.Política Educacional.

6.Didática e ou Metodologia do Ensino.

Os cursos de licenciatura no Brasil não podem ignorar a contribuição da História, da Sociologia, da Política e da Filosofia na área educacional, para a formação do professor, do profissional que vai atuar diretamente nas escolas brasileiras, junto à comunidade. Este trabalho educacional exige um profissional com uma formação diferenciada, particular, e até diria, especial. Um profissional capaz de articular a ciência com a realidade social, que articule os conceitos acadêmicos e científicos com a especificidade da realidade do aluno enquanto pessoa humana, enquanto cidadão.

Há bibliografia suficiente e conhecida para desenvolver estes conteúdos acadêmicos. Os cursos de Licenciatura no Brasil não podem ignorar as contribuições da ciência para a formação do professor.

A análise das últimas décadas do currículo das licenciaturas demonstrou que as mudanças são inexistentes, quando não, para dificultar, se impõem a alterações de nomenclatura e de aumento de cargas horárias de estágios que só contribuem para dificultar mais ainda a formação do professor.

Há necessidade de vontade política e de autoridade para se fazer um projeto acadêmico para um curso de LICENCIATURA; vontade política para chamar a si a responsabilidade e 
autoridade para realizar o enfrentamento necessário com o corporativismo que permeia nossas instituições. Vontade política para se elaborar um projeto acadêmico e de autoridade para o debate e a luta contra o corporativismo; há necessidade de se restabelecer o conceito de autoridade para tornar realidade um currículo de licenciatura neste país, a despeito do conceito de corporativismo predominante em nossas instituições.

Esta tarefa não é para um indivíduo nem tampouco para o partido, mas sim para um conjunto de professores preocupados com os cursos de licenciatura e, consequentemente, com a formação de professores para o Brasil. Com competência técnica, habilidade política e autoridade, pode-se transformar os cursos de Licenciatura, ou criar outros, em cursos que efetivamente trabalhem e desenvolvam um conteúdo acadêmico e científico , e se preocupe, ao mesmo tempo, com a democratização deste mesmo conhecimento. O que deve fazer a escola de ensino fundamental e médio, além de ensinar a ler e escrever, senão propiciar à comunidade o acesso à ciência?

\section{THE EDUCATION AREA IN THE DEGREE COURSE IN SOCIAL SCIENCES}

ABSTRACT: The study aims to analyze the curriculum of the education area in the degree course in Social Sciences. Initially, it presents a brief history of higher education in Brazil in recent decades. Next, is presented and discussed the evolution of the curriculum of the education area in the degree course in Social Sciences. Finally, presents criticisms and suggestions for a shift of the curriculum, considering a contribution to the courses for teachers.

KEYWORDS: Graduate. Teacher. Curriculum.

\section{REFERÊNCIAS}

HILSDORF, M. L. S História da educação brasileira: leituras. São Paulo: Pioneira Thomson Learning, 2003.

MACEDO, A. R. Educação superior no século XXI e a reforma universitária brasileira. Ensaio: Aval. Pol. Publ. Educ, Rio de Janeiro, v.13, n.47, p.127-148, abr./jun. 2005.

SAVIANI, D. Política e educação no Brasil. São Paulo: Cortez, 1987. 


\section{BIBLIOGRAFIA CONSULTADA}

CUNHA, L. A. Reforma universitária em crise: gestão, estrutura e território. Revista Avaliação: Revista da Rede de Avaliação Institucional da Educação Superior, Campinas, v.3, n.2, p.7-21, 1998.

CUNHA, L. A.; GOES, M. de. O golpe na educação. Rio de Janeiro: Zahar, 1988.

DRAIBE, S. As políticas sociais e neoliberalismo. São Paulo: Revista USP, 1993.

IMBERNÓN, F. Formação docente e profissional: formar-se para a mudança e a incerteza. São Paulo: Cortez, 2002.

LINDINGER, M. (Coord.). Políticas públicas de qualidade na educação básica. Brasília: CONSED, 1996. (Série Seminários).

MACEDO, A. R. O papel social da universidade. Estudos, Brasília, v.23, n.34, p.7-12, abr.2005.

MOREIRA, A. F. B. Currículo e multiculturalismo: desafios e tensões. In: LISITA, V. E. SOUSA, L. F. (Org.). Políticas educacionais, práticas escolares e alternativas de inclusão escolar. Rio de Janeiro: DP\&A, 2003. p.155-172.

ROSAR, M. F. F.; KRAWCZYC, N. R. Diferenças da homogeneidade: elementos para o estudo da política educacional na América Latina. Educação \& Sociedade, Campinas, n.75, p.33-47, 2001.

SANTOS, B. S. A crise dos paradigmas em Ciências Sociais e os desafios para o século XXI. Rio de Janeiro: Contraponto, 2001.

SAVIANI, D. Neo-liberalismo ou pós-liberalismo? Educação pública, crise do Estado e democracia na América Latina. In: VELLOSO, J. et al. Estado e Educação. Campinas: Papirus; São Paulo: CEDES, 1992. p.9-29. 